\title{
A CASE OF TRICUSPID ATRESIA WITH TRANSPOSITION OF THE GREAT VESSELS
}

\author{
BY \\ C. F. ROSS \\ From Ashford Hospital, Ashford, Middlesex
}

(RECEIVED FOR PUBLICATION JUNE 2, 1951)

Lack of development of the tricuspid valve is one of the rarer types of congenital heart disease. Before the advent of cardiac surgery it was of little more than academic interest, but now that such cases can be relieved surgically the condition assumes practical importance, and in cases of congenital heart disease every effort must be made to diagnose the anatomical defect.

\section{Incidence}

There is no trustworthy estimate of the incidence of congenital heart disease as a whole, still less of tricuspid atresia. Doubtless many infants have died with tricuspid atresia, on whom no post-mortem examination was made, with merely a diagnosis of congenital heart disease or even unrelated diagnoses, since many of them succumb to infections such as pneumonia, meningitis, septicaemia.

The first case to be recorded appears to be that of Sieveking (1854), and since then about 50 cases have been reported. Abbott (1936) found 16 cases of tricuspid atresia of developmental origin in her series of 1,000 cases of congenital heart disease. In 7,500 necropsies at the Philadelphia General Hospital, Szypulski (1937) found 111 patients with congenital heart disease, but not one of tricuspid atresia. Similarly, Rannels and Propst (1937) in 4,255 necropsies with 36 cases of congenital heart disease at the University Hospital of Pennsylvania found no case of this condition. Roberts (1937) gives an incidence of congenital heart disease of 1 , in his series of necropsies, in which again there was no case of tricuspid atresia. However, Fell, Gasul, Davis and Casas (1949) had five cases of the disease out of 135 cases of congenital cardiac anomalies at the Cook County Hospital in 1938-39. More recently Rossi, Grob and Bettex (1950) had one case out of 81 cases of congenital heart disease between 1947 and 1949 in Zürich. Campbell (1948) found 10 cases in 187 cases of cyanotic heart disease, and has since reported five patients who have had successful subclavian-pulmonary anastomosis with great improvement. It appears then that the incidence of tricuspid atresia lies somewhere between 1 and $4 \%$ of all congenital heart disease.

\section{Associated Defects}

The most constant cardiac defect accompanying tricuspid atresia is hypoplasia of the right ventricle. Rarely this may be completely absent (Taussig, 1936; Eisenberg and Gibson, 1941). Some authors (Taussig, 1936; Cooley, Sloan, Hanlon and Bahnson, 1950) are of the opinion that this is the essential lesion and that the failure of valve formation is secondary. There must be a patent foramen ovale because of the absence of the right atrioventricular orifice. In addition, an interatrial septal defect may be present, and its extent determines whether the heart will be functionally bilocular or trilocular. There is often a severe malformation of the pulmonary vascular tract, usually atresia (seven out of Abbott's 16 cases), and then for the circulation to be compatible with life there must be a patent ductus arteriosus. Partial or complete transposition of the pulmonary artery and aorta occurs in some instances, and Robinson and Howard (1948) divide cases of tricuspid atresia into two groups according to whether or not transposition is present. They state that the majority are without this added anomaly. A patent interventricular septum is often present (14 out of Abbott's 16 cases). A case with dextrocardia and situs inversus has been reported by Waite (1950). Defects in other organs do not appear to be common, but a case described by Dustin-Henry and Dustin (1947) had agenesis of the right kidney. Bàrbera (1941) reported a case of a female pseudohermaphrodite infant 7 days old with multiple congenital defects in addition to the tricuspid atresia.

\section{Aetiology}

The condition is developmental in origin. Lewis (1945) stressed the importance of the microscopic 
examination of the heart in cases with supposed foetal endocarditis and was of the opinion that probably many cases of congenital valvular defects had been incorrectly diagnosed as being of inflammatory nature.

A good deal has been written on the theory of the production of tricuspid atresia and transposition of the great vessels, and it is not proposed to consider this at length, since excellent reviews on the subject are available (Breslich, 1930; Bellet and Stewart, 1933; Lev and Saphir, 1937; Holder and Pick, 1939; Harris and Farber, 1939).

The first real contribution to the study of causation was that of Rauchfuss (1878) who thought that the developmental variety of tricuspid atresia was due to overgtowth and fusion of the endocardial cushions to the right of the interatrial septum. Manhoff and Howe (1945) were in agreement with this view. Vierordt (1898) was of the opinion that the condition was due to unequal division of the primitive atrium by a septum deviated too far to the right. Wieland (1914) and Mönckeberg (1924) supported this theory. Kühne (1906), however, postulated failure of the atrio-ventricular canal to shift enough to the right. Normally, the septum primum is directed towards the right margin of a single atrio-ventricular orifice, but the atrioventricular canal usually moves from left to right and so the free margin of the septum finally meets the lips of the orifice in the middle and gives the impulse to the endocardial cushions to fuse, with the production of two equally large canals. Spitzer (1923) developed a phylo-ontogenetic theory, in which the importance of torsion and haemodynamics was stressed. In his interpretation of Smetana's case (Smetana, 1929) he suggested that the tricuspid atresia was due to compression of the right venous ostium by a persistent bulbo-auricular crest and that the transposition of the great vessels was due to the inter-ventricular septum failing to rotate (Spitzer, 1929). Holder and Pick (1939), in reporting a case without transposition, point out that failure of the interventricular septum to rotate would result in narrowing and, finally, occlusion of the right venous ostium. This would also explain the existence of a patent interventricular septum, which is so commonly found in hearts with tricuspid atresia. For a detailed discussion of the embryology and aetiology of tricuspid atresia and transposition the reader is referred to the authors quoted above and to Keith (1909).

\section{Clinical Findings}

The main symptom is cyanosis, and some of the bluest babies seen with congenital heart disease are those with tricuspid atresia. Although many cases show cyanosis at birth, it is not uncommon for it to come on a few days later and to increase in the next few days, weeks or months. Sometimes cyanosis may be delayed for a month or two (Dustin-Henry and Dustin, 1947), up to a year (Soulié and Servelle, 1948), or even longer (Bellet and Stewart, 1933). Extremely rarely, cyanosis may be absent, usually due to the presence of transposition of the pulmonary artery and aorta (Hedinger, 1915). Characteristically the cyanosis is greatly increased by moving about, crying and feeding. It is interesting that Sieveking's (1854) original case did not show cyanosis until the day of death at 6 weeks of age. Since most of the patients are only a few months old, finger or toe clubbing is usually absent, but in older children it may be marked. Dyspnoeic attacks are a common feature. Cardiac murmurs may be present, but they are by no means constant. Their presence depends entirely on intra-cardiac pressure relationships and associated lesions, but, in spite of gross anatomical defects, murmurs may be absent. The liver and spleen may be enlarged and if the interatrial communication is small, the former will show presystolic pulsation (Waite, 1950). Vesell (1949) has described a sign in tricuspid stenosis which should theoretically be present in tricuspid atresia. This is the presence of a strong presystolic venous impulse over the jugular vein.

\section{Diagnosis}

In view of the success of surgical operations on the heart, the diagnosis of congenital heart lesions is now much more important. Tricuspid atresia is one which can be differentiated more easily than some, but as recently as 1936 no case had been diagnosed in life (Brown, 1936), but with the ancillary methods now at our disposal, few cases should go unrecognized. Fortunately, tricuspid atresia can be diagnosed in most instances without recourse to all of the modern methods of investigation, and only two will be considered here.

Radiology. The classical appearances in plain $\mathrm{x}$-ray films of the chest are as follows according to Taussig $(1936,1947)$ and others. (1) The heart is rectangular or boot-shaped and makes a sharp angle with the sternum due to the absence of the shadow normally cast by the pulmonary conus, but the overall cardiac area is within normal limits. (2) The left side of the heart is greatly enlarged and the shadow is at right angles to the sternum. (3) There is a concave upper margin to the heart shadow. (4) The aortic arch is narrow and there is the appearance of a single vessel at the base of the heart. (5) In the left antero-oblique position, the right ventricle is small or indecipherable. With these findings, a diagnosis of tricuspid atresia may 




Fig. 1.-Drawing of heart before opening.

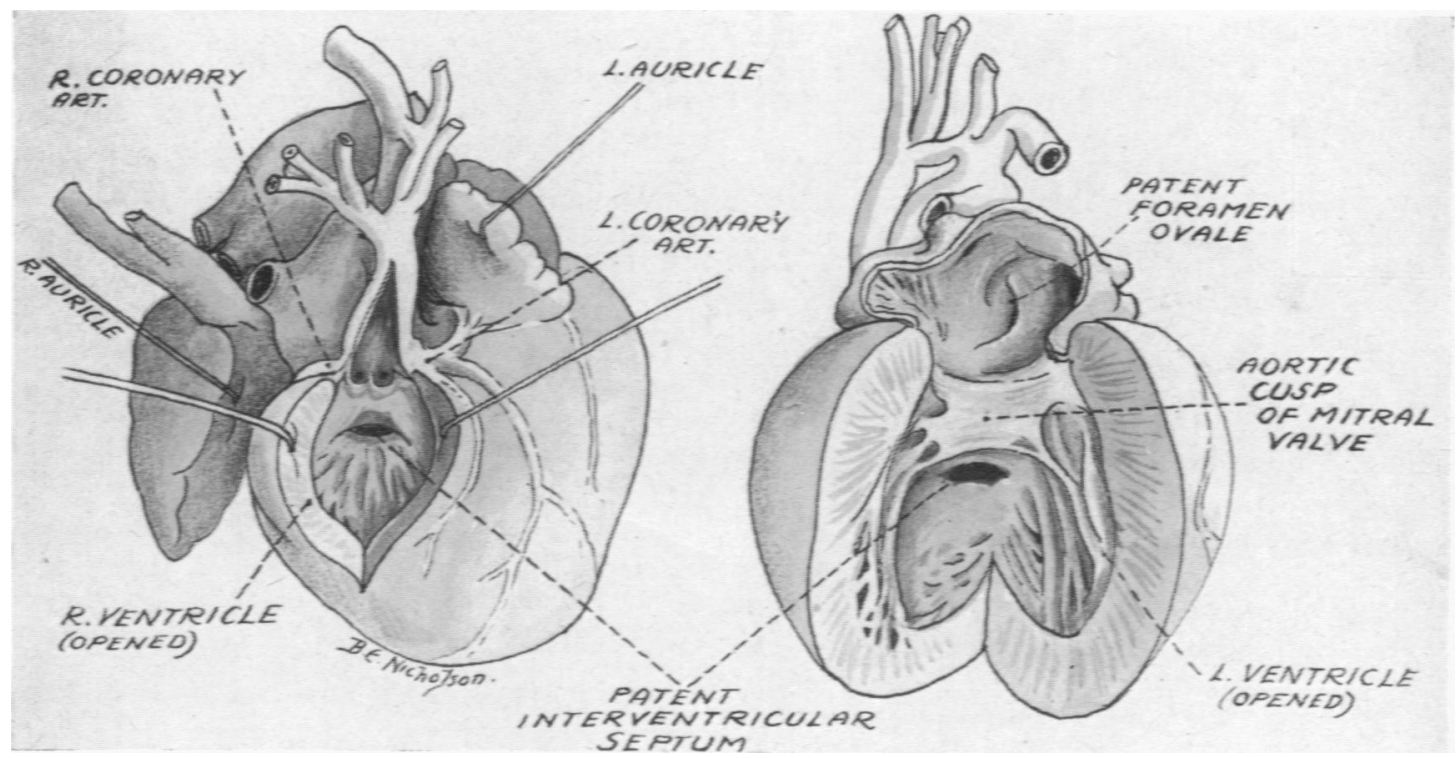

Fig. 2.-Drawing of heart after opening. 
be strongly suspected, but Eisenberg and Gibson (1941) reported a case with an anomaly in which there was no concavity in the shadow of the area of the pulmonary conus. If cyanosis is mild, the co-existence of transposition of the great vessels is highly probable (Robinson and Howard, 1948). If surgery is to be considered, angiocardiography is a useful part of the radiological examination, for it evaluates the size of the interatrial communication on which the success of surgical procedures may depend. In a study of angiocardiography in congenital heart disease of the cyanotic type Cooley et al. (1950) stressed that this method of investigation does not distinguish between hypoplasia of the right ventricle alone and that associated with tricuspid atresia. They found two cases of right ventricular hypoplasia without the valvular defect. This is further evidence in support of the concept that the hypoplastic right ventricle is the fundamental abnormality and the atresia of the tricuspid valve a concomitant defect. Angiocardiography clarifies the impressions received from other data and also demonstrates anomalies of the great vessels. The typical appearances are shown in photographs by Wood (1950) and Gasul, Fell, Marino and Davis (1949). The main findings in the dextro-angiocardiogram in uncomplicated cases are no right ventricle, no pulmonary artery and filling of the left atrium and ventricle.

Electrocardiography. Most cases of cyanotic heart disease of congenital origin show right ventricular preponderance, but those with tricuspid atresia show a very definite left ventricular preponderance. This was first shown by Rihl, Terplan and Weiss (1929) although Papillon and Mourrut (1931) claimed priority in this respect. Statements that left axis deviation was pathognomonic of tricuspid atresia (e.g. Taussig, 1936; Miale, Millard, Beno and Custer, 1948) have been shown to be untrue by other workers. Schnitker (1940) found that 11 out of his 13 cases of Fallot's tetralogy had right ventricular preponderance, but Gasul et al. (1949) point out that left axis deviation can occur in Fallot's tetralogy with patent foramen ovale, and mention a case to be published in detail at a future date. In the presence of dextrocardia or gross conduction defects there may be a similar finding (Brown, 1936). Eisenberg and Gibson (1941) also say that left axis deviation is not incompatible with Fallot's tetralogy, particularly when this is complicated by other cardiac defects. In a study of 527 patients with morbus caeruleus Donzelot, Durand, Métianu and Vlad (1950) found 22 with left axis deviation, 18 of whom had tricuspid atresia. The others were two cases of uncertain diagnosis, one with pulmonary stenosis and partial trans- position and one with coarctation of the aorta (infantile type). Since the right atrium is often hypertrophied, a high notched $P$ wave may be an additional sign of value. In general, one should think of tricuspid atresia in a cyanosed child with left ventricular preponderance in the E.C.G. and a boot-shaped heart in the chest $x$-ray. The other, but rarer, condition in which left axis deviation is a feature is the infantile type of coarctation of the aorta. However, this is usually in children over two years of age, whereas tricuspid atresia is nearly always manifest much before this.

\section{Prognosis}

Without surgical treatment most of the patients with tricuspid atresia are dead within a year, though there are exceptions; for example, the cases of Smetana (1929); Moser (1936), Soulié and Servelle (1948) and one of those described by Cooley et al. (1950). Death occurs from cardiac insufficiency and may be sudden. In the pre-antibiotic era many patients died of infections. If transposition is present, this is beneficial and may enable life to be sustained for many years. Hedinger's patient (1915) lived to 56 without cardiac symptoms and died from an unrelated cause. If surgical intervention is possible, the prognosis is vastly improved, but it is too early yet to judge how successful will be the final outcome.

\section{Case Report}

J.F.S., a boy, was born on June 23, 1949, after a normal labour lasting 13 hours, and weighed $6 \mathrm{lb} .13 \mathrm{oz}$. There was no history of illness in the mother during the pregnancy, and her blood was Rh-positive (anti-D). Apart from marked physiological jaundice and some atelectasis the infant appeared normal until a week later, when his general condition became poor and periodic attacks of dyspnoea occurred. Some cyanosis of the extremities was noted at this time. Clinical examination revealed no abnormality in the chest apart from signs of non-expansion at the left base, but the liver was eniarged and hard, and the spleen was easily palpable. Four days later there were lung signs suggestive of bronchopneumonia, dyspnoeic attacks became more frequent, and cyanosis was marked. On July 7 the infant's condition showed some improvement, but on the following day he suddenly became deeply cyanosed and collapsed and died during a feed, at the age of 15 days.

Post-mortem Findings. External examination showed deep cyanosis of the lips and nail-beds. Icterus was not noticeable. The cord had separated and the umbilicus was normal. The testicles were impalpable. The body weight was $6 \mathrm{lb} .11 \mathrm{oz} .(3 \cdot 1 \mathrm{~kg}$.).

There was no evidence of disease in the intracranial contents. The mouth and neck structures were normal. Each pleural cavity contained about $30 \mathrm{ml}$. $(1 \mathrm{oz}$.) of clear, straw-coloured fluid. Both lungs showed patchy atelectasis, mostly basal, but no other abnormality. The heart weighed $45 \mathrm{~g}$. and measured $42 \mathrm{~mm}$. from apex to 
base, and $50 \mathrm{~mm}$. in its transverse diameter at the base. The right atrium and auricle were enlarged, and on opening them the muscle was seen to be much trabeculated and thickened $(2.5 \mathrm{~mm}$. average thickness). The foramen ovale was patent and measured $7 \mathrm{~mm}$. in diameter, but no tricuspid orifice could be found. The endocardium was smooth and there was nothing to suggest an inflammatory condition in any part of the heart. The coronary sinus opened in the normal position and had a large valve. Examination of the great vessels showed complete transposition of the pulmonary artery and aorta, the latter arising from a rudimentary right ventricle $(25 \times 10 \mathrm{~mm}$.) in the thickened muscle of the left ventricle. The first vessel to arise came off the aorta $2 \mathrm{~cm}$. from the aortic valve, which was normal. The vessel was an innominate artery which then divided into the right subclavian and common carotid arteries. The next branch was the left common carotid, and just distal to this the aorta continued to the left and then divided to form the left subclavian artery and a very short, rather narrower vessel (ductus arteriosus). The pulmonary trunk arose from the left ventricle and was a large vessel $10 \mathrm{~mm}$. in diameter, having a tricuspid semilunar valve at its orifice. It ascended for $15 \mathrm{~mm}$. and then gave rise to three narrower vessels, two supplying the lungs, the right pulmonary artery being a continuation directly backwards and the left pulmonary artery proceeding obliquely to the left. The third vessel continued upwards to communicate with the aorta (ductus arteriosus). The diameter of the main vessel then slightly increased and continued downwards as the descending aorta (Fig. 1). The coronary arteries arose from the transposed aorta in their usual position, the left coronary running to the left in the groove between left auricle and left ventricle, with a large branch arising just outside the aorta and descending obliquely to the left across the anterior surface of the left ventricle. The right coronary ran downwards and backwards between the transposed pulmonary artery and upper portion of the right ventricle covered by the right auricular appendage, and gave rise to a number of branches descending the posterior surface of the left ventricle. On opening the left atrium, which was not enlarged, a normal mitral valve was visible, the orifice being $35 \mathrm{~mm}$. in circumference. The left ventricle was enlarged (30 $25 \mathrm{~mm}$ ) and thickened $(8 \mathrm{~mm}$.). The mitral orifice opened into the left half of the cavity, fully half of the latter being to the right of the aortic cusp of the mitral valve and opening into the transposed pulmonary trunk. Just below the pulmonary valve was a bridge of thick muscle below which was an opening $10 \times 5 \mathrm{~mm}$. communicating with the rudimentary right ventricle, i.e. a patent interventricular septum. The venous side of the heart appeared normal (Fig. 2).

In the abdomen the relevant findings were a grossly congested liver (140 g.) and spleen (11 g.): a large left kidney ( 24 g.) and a small right kidney $(8$ g.) showing hydronephrosis and hydro-ureter due to intramural constriction of the ureter in the bladder wall (Fig. 3).

Histology. In the liver there was acute congestion, slight peri-portal fatty changes and scattered islets of haemopoiesis. Eosinophils were numerous in the portal tracts. There was acute congestion of the sinusoids and pulp of the spleen. Patchy atelectasis, capillary congestion and thickening of the arterioles due to an increase of muscle and elastic tissue in the media were seen in the lungs.

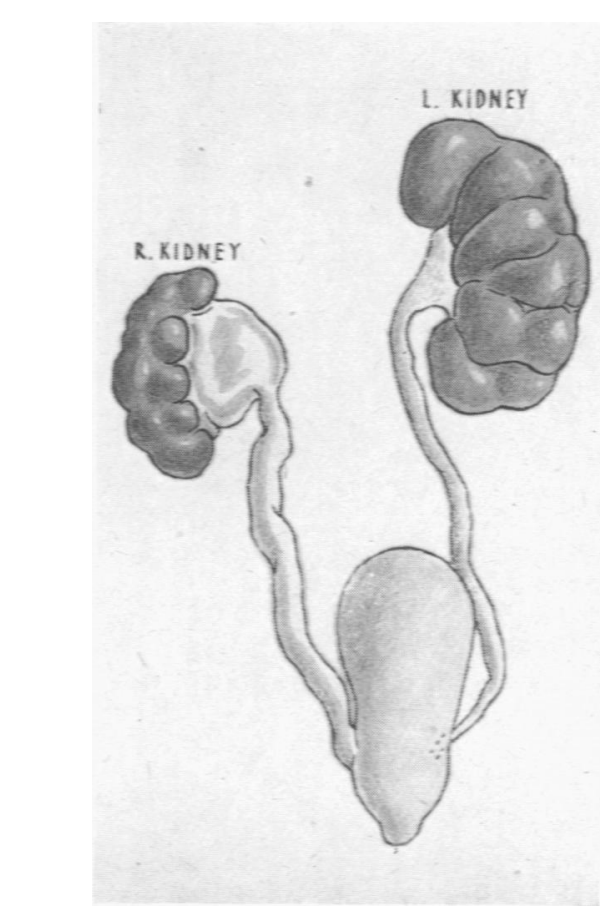

FIG. 3.-Drawing of kidneys. ureters and bladder.

\section{Discussion}

This heart showed many of the anatomical characters already reported in other cases of tricuspid atresia and is almost a replica of that described by Wason (1934). There can be no doubt that the condition was developmental, and it corresponds to Spitzer's type IV. The presence of a congenital stenosis of one ureter was probably coincidental. Clinically, the absence of heart murmurs rather suggested that the cyanosis was of respiratory origin, especially since signs of atelectasis were present. Had radiological and electrocardiographical examination been possible, it is likely that the diagnosis would have been manifest. Although mixing arterial and venous blood was occurring (Fig. 4), oxygenation was adequate except when the patient was moving about, crying or feeding. The existence of a small patent foramen ovale necessitated hypertrophy of the right atrium, and the left ventricle was large because it had to supply blood to the lungs as well as to provide the systemic circulation. It is not clear what caused the 
attacks of dyspnoea. There was no evidence of left ventricular failure, and they may possibly have been of respiratory origin. Death appeared to have been due to acute congestive heart failure.

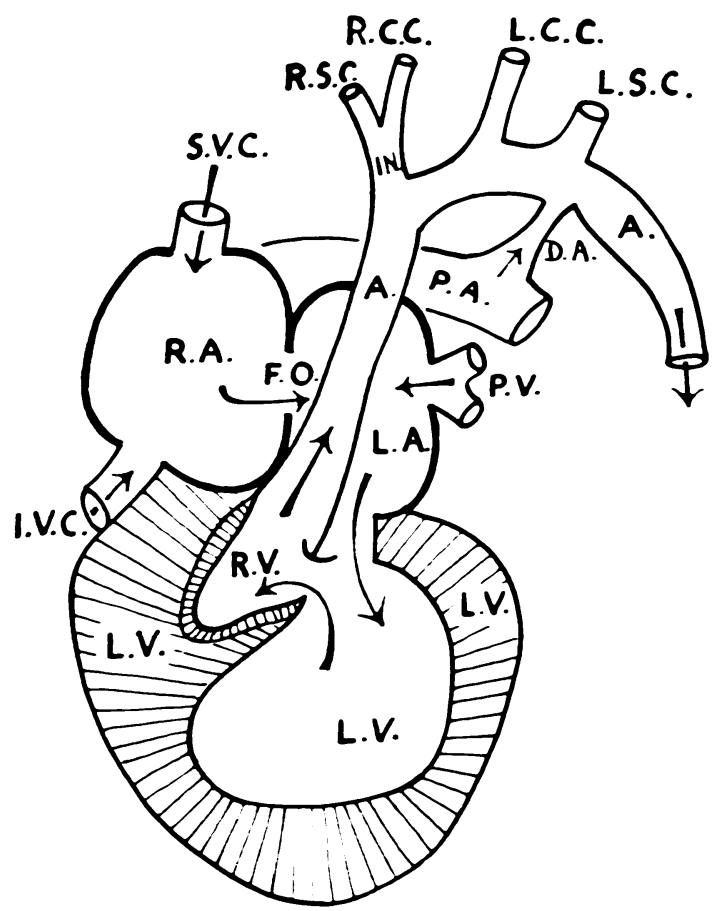

Fig. 4.-Diagrammatic sketch of heart to show the direction of the circulation.

S.V.C., superior vena cava: I.V.C., inferior vena cava; R.A., right atrium; F.O., patent foramen ovale; L.A., left atrium: P.V., pulmonary veins; L.V., left ventricle; R.V., right ventricle; A., aorta; I.N., innominate artery: R.S.C., right subclavian artery R.C.C., right common carotid artery; L.C.C., left common carotid artery; L.S.C., left subclavian artery; P.A., pulmonary artery; D.A., patent ductus arteriosus.

\section{Summary}

A short account of the clinical and pathological manifestations of tricuspid atresia is given. Its diagnosis is discussed and a case reported with this condition with, in addition, complete transposition of the aorta and pulmonary artery.

I am grateful to Dr. Charles Pinckney for permission to publish this case. The drawings were executed by Miss B. E. Nicholson, to whom I tender my thanks.

\section{REFERENCES}

Abbott, M. E. (1936). 'Atlas of Congenital Cardiac Disease,' p. 61. New York.

Bàrbera, V. (1941). Cuore e Circol., 25, 11.

Bellet, S. and Stewart, H. L. (1933). Amer. J. Dis. Child., 45, 1247.
Breslich, P. J. (1930). Trans. Chicago path. Soc., 13, 307. (1930). Arch. Path., Chicago, 10, 206.

Brown, J. W. (1936). Archives of Disease in Childhood, 11, 275.

Campbell, M. (1948). Guy's Hosp. Rep., 97, 31.

Cooley, R. N., Sloan, R. D., Hanlon, C. R. and Bahnson, H. T. (1950). Radiology, 54, 848.

Donzelot, E., Durand, M., Métianu, C. and Vlad, P. (1950). Arch. Mal. Coeur., 43, 577.

Dustin-Henry, M. J. and Dustin, P. (1947). Acta cardiol., Brux., 2, 175.

Eisenberg, G. and Gibson, S. (1941). J. Pediat., 19, 452.

Fell, E. H., Gasul, B. M., Davis, C. B. and Casas, R. (1949). Arch. Surg., Chicago, 59, 445.

Gasul, B. M., Fell, E. H., Marino, J. J. and Davis, C. B. (1949). Amer. J. Dis. Child., 78, 16.

Harris, J. S. and Farber, S. (1939). Arch. Path., Chicago, 28, 427.

Hedinger, E. (1915). Zbl. allg. Path. path. Anat., 26, 529.

Holder, E. C. and Pick, J. (1939). J. tech. Meth., 19, 135.

Keith, A. (1909). Lancet, 2, 359.

Kühne, M. (1906). Jb. Kinderheilk., 63, 235.

Lev, M. and Saphir, O. (1937). J. tech. Meth., 17, 126.

Lewis, T. (1945). Clin. Sci., 5, 261.

Manhoff, L. J. and Howe, J. S. (1945). Amer. Heart J., 29, 90.

Miale, J. B., Millard, A. L., Beno, T. J. and Custer, G. S. (1948). Ibid., 36, 438.

Mönckeberg, J. G. (1924). Handbuch der speziellen pathologischen Anatomie und Histologie, ed. Henke, F., and Lubarsch, O., p. 63. Berlin.

Moser, A. (1936). Z. KreislForsch., 28, 521.

Papillon, P. H. and Mourrut, E. (1931). Bull. Soc. Pédiat. Paris, 29, 503.

Rannels, H. W. and Propst, J. H. (1937). J. tech. Meth., $17,113$.

Rauchfuss, C. L. (1878). 'Handbuch der Kinderkrankheiten,' p. 100. Vol. 4, pt. 1, ed. Gerhardt, C. Tübingen.

Rihl, J., Terplan, K. and Weiss, F. (1929). Med. Klinik., 25, 1543.

Roberts, J. T. (1937). J. tech. Meth., 17, 97.

Robinson, A. and Howard, J. E. (1948). Amer. J. Dis. Child., 75, 575.

Rossi, E., Grob, M. and Bettex, M. (1950). Helv. paediat. Acta, 5, Suppl. 49.

Schnitker, M. A. (1940). - The Electrocardiogram in Congenital Cardiac Disease,' p. 96. Cambridge, Mass.

Sieveking (1854). Trans. path. Soc. Lond., 5, 97.

Smetana, H. (1929). Z. KreislForsch., 21, 513.

Soulié, P. and Servelle, M. (1948). Mém. Acad. Chir., Paris, 74, 422.

Spitzer, A. (1923). Virchows Arch., 243, 81

- (1929). Z. KreislForsch., 21, 523.

Szypulski, J. T. (1937). J. tech. Meth., 17, 119

Taussig, H. B. (1936). Johns Hopk. Hosp. Bull., 59, 435. (1947). Congenital Malformations of the Heart; p. 79. Commonwealth Fund. New York.

Vesell, H. (1949). Amer. J. Med., 7, 497.

Vierordt, H. (1898). Die angeborenen Herzkrankheiten. In 'Specielle Pathologie und Therapie,' vol. 15, p. 198, pt. 1 (abt. 2), ed. Nothnagel, H. Vienna.

Waite, C. L. (1950). Clin. Proc. Child. Hosp., Wash., $6,195$.

Wason, I. (1934). J. tech. Meth., 13, 106.

Wieland, E. (1914). Jb. Kinderheilk., 79, 320.

Wood, P. (1950). 'Diseases of the heart and circulation,' p. 251. London. 